\title{
Development of thermophysical calculator for stainless steel casting alloys by using CALPHAD approach
}

\author{
*In-Sung Cho', K. D. Savelyev², and V. M. Golod ${ }^{2}$ \\ 1. Korea Institute of Industrial Technology, Korea \\ 2. Peter the Great St. Petersburg Polytechnic University, Russia
}

\begin{abstract}
The calculation of thermophysical properties of stainless steel castings and its application to casting simulation is discussed. It is considered that accurate thermophysical properties of the casting alloys are necessary for the valid simulation of the casting processes. Although previous thermophysical calculation software requires a specific knowledge of thermodynamics, the calculation method proposed in the present study does not require any special knowledge of thermodynamics, but only the information of compositions of the alloy. The proposed calculator is based on the CALPHAD approach for modeling of multi-component alloys, especially in stainless steels. The calculator proposed in the present study can calculate thermophysical properties of eight-component systems on an iron base alloy (Fe-C-Si-Cr-Mn-Ni-Cu-Mo), and several Korean standard stainless steel alloys were calculated and discussed. The calculator can evaluate the thermophysical properties of the alloys such as density, heat capacity, enthalpy, latent heat, etc, based on full Gibbs energy for each phase. It is expected the proposed method can help casting experts to devise the casting design and its process easily in the field of not only stainless steels but also other alloy systems such as aluminum, copper, zinc, etc.
\end{abstract}

Key words: stainless steels; casting simulation; thermophysical properties; CALPHAD

CLC numbers: TP391.99 Document code: A

Article ID: 1672-6421(2017)05-353-06

F om several decades ago, computer simulation is utilized on most casting processes, and is considered to be inevitable tools for designing casting products and processes. The computer simulation is applied to design not only casting process, but also the casting parts. It also plays an important role on initial product design and reducing defects during production stage. However, one of the important variables of the computer simulation in casting processes are thermophysical properties of the casting alloys, and generally the properties are obtained by thermal analysis and experiments. Recently, a number of studies on calculation of thermophysical properties have been carried out, therefore the calculation techniques can replace experiments. However, few

\section{*In-Sung Cho}

Male, born in 1968, Ph. D. Principal Researcher of Korea Institute of Industrial Technology. He has been working in the field of casting design and evaluation by using computer tomography and CAE. His academic research has led to the publication of more than 10 papers, in journals such as International Journal of Cast Metals Research, and ISIJ International.

E-mail: ischo@kitech.re.kr

Received: 2017-08-14; Accepted: 2017-09-04 studies were carried out on the user-friendly calculation of thermophysical properties of the casting alloys, though it is still difficult for common casting engineers to use the commercial thermodynamic software. The final goal of the present study is to develop a simple and easy calculation tool of thermodynamic properties of casting alloys for non-skilled foundry engineers.

\section{Thermodynamic models for multi-component alloys}

CALPHAD approach was used for calculating thermophysical properties of stainless steels. CALPHAD is based on evaluating Gibbs free energy by using thermodynamic parameters from various phase diagrams published. The proposed models for approximation of full Gibbs energy of phases of multicomponent alloys system are used, as published in the previous articles ${ }^{[1-2]}$. In the majority of multi-component alloy systems, liquid and solid phases are considered as substitutional solution and interstitional solution. 
Detailed description of the approximation of full Gibbs free energy is explained in the previous article ${ }^{[1]}$.

\subsection{Approximation of phases of other sublattices}

In order to calculate the phases of other sublattices such as carbides $\left(\mathrm{Me}_{23} \mathrm{C}_{6}, \mathrm{Me}_{6} \mathrm{C}\right)$ and intermetallics which can be usually found in the stainless steels, Eqs. (1) to (3) were used in the present study. The present study deals with $(\mathrm{Cr}, \mathrm{Fe}, \mathrm{Mn}$, $\mathrm{Ni})_{20}(\mathrm{Cr}, \mathrm{Fe}, \mathrm{Mn}, \mathrm{Mo}, \mathrm{Ni})_{3} \mathrm{C}_{6}$, in case of $\mathrm{Me}_{23} \mathrm{C}_{6}$ type carbides calculation.

For example, the full Gibbs energy equation is described as follows:

$$
\begin{aligned}
G_{m}= & y_{\mathrm{C}}^{1} y_{\mathrm{Cr}}^{2}{ }^{\circ} G_{\mathrm{Cr}, \mathrm{Cr}: \mathrm{C}}+y_{\mathrm{Cr}}^{1} y_{\mathrm{Fe}}^{2}{ }^{\circ} G_{\mathrm{Cr}, \mathrm{Fe}: \mathrm{C}}+y_{\mathrm{Fe}}^{1} y_{\mathrm{Cr}}^{2}{ }^{o} G_{\mathrm{Fe}, \mathrm{Cr}: \mathrm{C}} \\
& +y_{\mathrm{Fe}}^{1} y_{\mathrm{Fe}}^{2}{ }^{\circ} G_{\mathrm{Fe}, \mathrm{Fe}: \mathrm{C}}+\mathrm{RT}\left[20\left(y_{\mathrm{Cr}}^{1} \ln y_{\mathrm{Cr}}^{1}+y_{\mathrm{Fe}}^{1} \ln y_{\mathrm{Fe}}^{1}\right)\right. \\
& \left.+3\left(y_{\mathrm{Cr}}^{2} \ln y_{\mathrm{Cr}}^{2}+y_{\mathrm{Fe}}^{2} \ln y_{\mathrm{Fe}}^{2}\right)\right]+{ }^{e x} G m
\end{aligned}
$$

where

$$
\begin{aligned}
e^{e x} G m= & y_{\mathrm{C}}^{1} y_{\mathrm{Fe}}^{1}\left(y_{\mathrm{Cr}}^{2} J_{\mathrm{Cr}, \mathrm{Fe}, \mathrm{Cr}: \mathrm{C}}+y_{\mathrm{Fe}}^{2} J_{\mathrm{Cr}, \mathrm{Fe}, \mathrm{Fe}: \mathrm{C}}\right) \\
& +y_{\mathrm{Cr}}^{2} y_{\mathrm{Fe}}^{2}\left(y_{\mathrm{Cr}}^{1} J_{\mathrm{Cr}, \mathrm{Fe}, \mathrm{Cr}: \mathrm{C}}+y_{\mathrm{Fe}}^{1} J_{\mathrm{Cr}, \mathrm{Fe}, \mathrm{Fe}: \mathrm{C}}\right) \\
& +y_{\mathrm{Cr}}^{1} y_{\mathrm{Fe}}^{2} y_{\mathrm{Cr}}^{2} y_{\mathrm{Fe}}^{2}\left(y_{\mathrm{Cr}}^{2} J_{\mathrm{Cr}, \mathrm{Fe}, \mathrm{Cr}: \mathrm{C}}+y_{\mathrm{Fe}}^{2} J_{\mathrm{Cr}, \mathrm{Fe}: \mathrm{Cr}, \mathrm{Fe}: \mathrm{C}}\right)
\end{aligned}
$$

${ }^{e x} G_{m}$ designates excessive Gibbs energy describing interaction between components of an alloy; $y_{s}^{i}$ designates a part of positions in sublattice $s$, occupied with a component $i$; the conception of vacancy in the model is not considered.

For the intermetallic compounds, namely sigma phase structure, is formulated as $(\mathrm{Fe}, \mathrm{Mn}, \mathrm{Ni})_{8}(\mathrm{Cr}, \mathrm{Mo})_{4}(\mathrm{Cr}, \mathrm{Fe}, \mathrm{Mn}$,

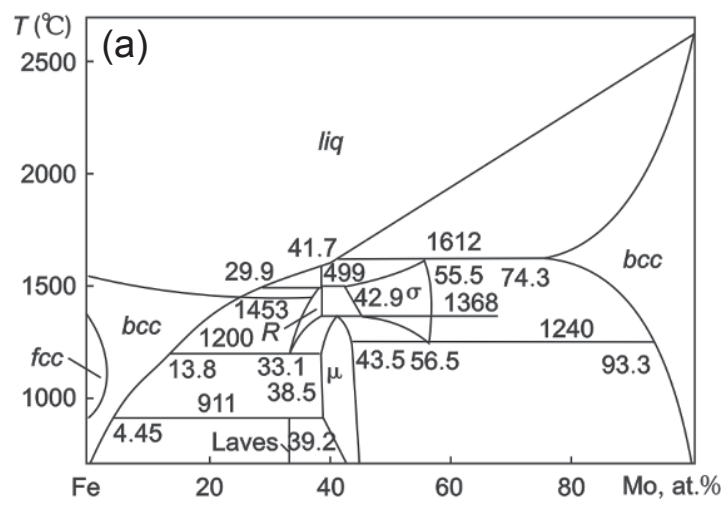

Mo, Ni, Si) ${ }_{18}$. For example, the Gibbs energy of a sigma-phase in system Fe-Cr-Mo is,

$$
\begin{aligned}
G_{m}= & y_{\mathrm{Cr}}^{2}\left(y_{\mathrm{Cr}}^{3}{ }^{\circ} G_{\mathrm{Fe}: \mathrm{Cr}, \mathrm{Cr}}+y_{\mathrm{Fe}}^{3}{ }^{\circ} G_{\mathrm{Fe}: \mathrm{Cr}, \mathrm{Fe}}+y_{\mathrm{Mo}}^{3}{ }^{\circ} G_{\mathrm{Fe}: \mathrm{Cr}, \mathrm{Mo}}\right)+ \\
& y_{\mathrm{Mo}}^{2}\left(y_{\mathrm{Cr}}^{3}{ }^{0} G_{\mathrm{Fe}: \mathrm{Mo}, \mathrm{Cr}}+y_{\mathrm{Fe}}^{3}{ }^{\circ} G_{\mathrm{Fe}: \mathrm{Mo}, \mathrm{Fe}}+y_{\mathrm{Mo}}^{3} G_{\mathrm{Fe}: \mathrm{Mo}, \mathrm{Mo}}\right)+ \\
& 4 R T\left(y_{\mathrm{Cr}}^{2} \ln y_{\mathrm{Cr}}^{2}+y_{\mathrm{Mo}}^{2} \ln y_{\mathrm{Mo}}^{2}\right)+ \\
& 18 R T\left(y_{\mathrm{Cr}}^{3} \ln y_{\mathrm{Cr}}^{3}+y_{\mathrm{Fe}}^{3} \ln y_{\mathrm{Fe}}^{3}+y_{\mathrm{Mo}}^{2} \ln y_{\mathrm{Mo}}^{2}\right)+ \\
& y_{\mathrm{Cr}}^{2} y_{\mathrm{Cr}}^{3} y_{\mathrm{Mo}}^{3} J_{\mathrm{Fe}: \mathrm{Cr}: \mathrm{Cr}, \mathrm{Mo}}+y_{\mathrm{Cr}}^{2} y_{\mathrm{Fe}}^{3} y_{\mathrm{Mo}}^{3} J_{\mathrm{Fe}: \mathrm{Cr}: \mathrm{Fe}, \mathrm{Mo}}+ \\
& y_{\mathrm{Mo}}^{2} y_{\mathrm{Cr}}^{3} y_{\mathrm{Mo}}^{3} J_{\mathrm{Fe}: \mathrm{Mo}: \mathrm{Cr}, \mathrm{Mo}}+y_{\mathrm{Mo}}^{2} y_{\mathrm{Cr}}^{3} y_{\mathrm{Fe}}^{3} J_{\mathrm{Fe}: \mathrm{Mo}: \mathrm{Cr}, \mathrm{Fe}}
\end{aligned}
$$

\subsection{Phase diagram database construction}

The calculator proposed in the present study can calculate the thermophysical properties of eight-component systems on an iron base alloy (Fe-C-Si-Cr-Mn-Ni-Cu-Mo). Parameters of interaction are selected by comparison of calculated phase diagram for a number of systems and results of known experimental studies. The phase diagrams used in the present study are as follows ${ }^{[2-15]}$ : Fe-C, Fe-C-Si, Fe-C-Cr, Fe-C-Mn, Fe$\mathrm{C}-\mathrm{Ni}, \mathrm{Fe}-\mathrm{Cu}, \mathrm{Fe}-\mathrm{C}-\mathrm{Cr}-\mathrm{Ni}, \mathrm{Fe}-\mathrm{C}-\mathrm{Cr}-\mathrm{Mn}, \mathrm{Mn}-\mathrm{Si}, \mathrm{Cr}-\mathrm{Si}, \mathrm{Cu}-\mathrm{Si}$, $\mathrm{Cr}-\mathrm{Cu}, \mathrm{Cu}-\mathrm{Ni}, \mathrm{Fe}-\mathrm{Cu}$, Fe-C-Mo, Fe-Cr-Mo, Fe-C-Cr-Mo, C-Ni$\mathrm{Si}, \mathrm{Cu}-\mathrm{Fe}-\mathrm{Mo}, \mathrm{Cr}-\mathrm{Fe}-\mathrm{Si}$, Fe-Ni-Si, Cr-Ni-Si, Fe-Mn-Si, Cr-Fe$\mathrm{Mn}, \mathrm{Mo}-\mathrm{Ni}, \mathrm{C}-\mathrm{Cr}-\mathrm{Mo}, \mathrm{Cr}-\mathrm{Cu}-\mathrm{Ni}$, Mo-Si.

For the evaluation of the accuracy of the calculator, phase diagram for Fe-C system was compared with the previous study $^{[1]}$, and the calculated results are within the range of $0.05 \mathrm{at} . \%$ in composition and $5 \mathrm{~K}$ in temperature.

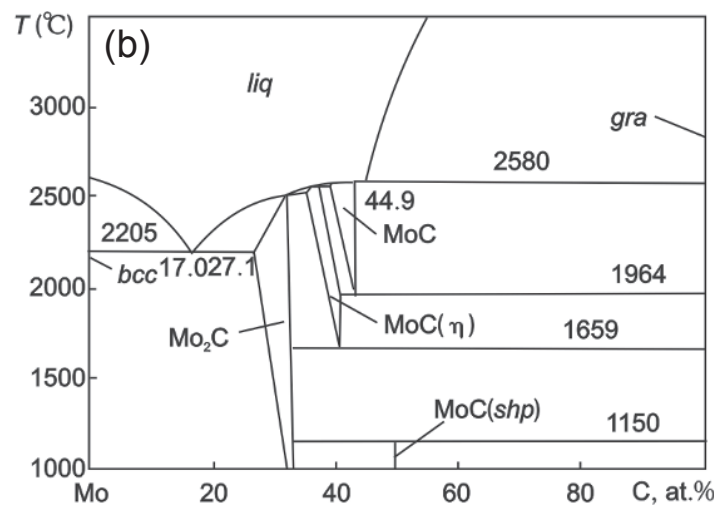

Fig. 1: Calculated phase diagrams for Fe-Mo (a) and Mo-C system (b)

Figure 1 shows the calculated phase diagrams for Fe-Mo and Mo-C, for the verification of adequacy.

For the binary phase diagram for alloys containing molybdenum, following phases are found during solidification:

(1) Fe-Mo: bcc, fcc, $\sigma, \mathrm{R}, \mu$.

(2) Mo-C: bcc, $\mathrm{Mo}_{2} \mathrm{C}$, graphite, $\mathrm{MoC}(\eta), \mathrm{MoC}(\mathrm{shp})$.

(3) Mo-Si: bcc, $\mathrm{Si}, \mathrm{Mo}_{3} \mathrm{Si}, \mathrm{Mo}_{5} \mathrm{Si}_{3}, \mathrm{MoSi}_{2}$.

(4) Mo-Ni: bcc, fcc, $\delta, \mathrm{Ni}_{3} \mathrm{Mo}, \mathrm{Ni}_{4} \mathrm{Mo}$

(5) $\mathrm{Mo}-\mathrm{Cu}:$ bcc, fcc.

(6) Mo-Cr: bcc.

The fragments of liquid surfaces for systems Fe-C-Cr (the area of formation of carbide $\mathrm{Me}_{23} \mathrm{C}_{6}$ is included), $\mathrm{Fe}-\mathrm{C}-\mathrm{Mo}$,
$\mathrm{Fe}-\mathrm{Cr}-\mathrm{Mo}$, Fe-Mo-Ni are also calculated. Figure 2 shows the calculated phase diagram for $\mathrm{Fe}-\mathrm{C}-\mathrm{Cr}$ and $\mathrm{Fe}-\mathrm{C}-\mathrm{Mo}$.

The calculator proposed in this paper can calculate thermophysical properites of Fe-based alloys of Fe-C-Si-Cr-Mn$\mathrm{Ni}-\mathrm{Cu}-\mathrm{Mo}$ system, containing $\mathrm{C}$ from 0.05 to $0.1 \mathrm{wt} . \%$, Si up to 3 wt. $\%$, $\mathrm{Cu}$ up to $3 \mathrm{wt} . \%$, Mn up to $5 \mathrm{wt} . \%$, $\mathrm{Cr}$ up to $30 \mathrm{wt} . \%$, $\mathrm{Ni}$ up to $8 \mathrm{wt} . \%$ and Mo up to $5 \mathrm{wt} . \%$. The following phases are considered: fcc solid solution, bcc solid solution, graphite, cementite, $\mathrm{Fe}_{2} \mathrm{Si}, \mathrm{Fe}_{8} \mathrm{Si}_{2} \mathrm{C}, \mathrm{Me}_{7} \mathrm{C}_{3}, \mathrm{SiC}, \mathrm{Me}_{6} \mathrm{C}, \mathrm{Me}_{2} \mathrm{C}, \xi$-carbide, $\operatorname{MoC}\left(\eta\right.$, shp), $\sigma, \mu, \mathrm{R}, \mathrm{P}$, chi-phase, $\mathrm{Cr}_{3} \mathrm{Si}, \mathrm{MeSi}, \mathrm{Me}_{3} \mathrm{Si}_{2} \mathrm{Me}_{5} \mathrm{Si}_{3}$, $\mathrm{Me}_{5} \mathrm{C}_{2}, \mathrm{Mo}_{3} \mathrm{Si}, \mathrm{Mo}_{5} \mathrm{Si}_{3}, \mathrm{MoSi}_{2}, \delta, \mathrm{Ni}_{3} \mathrm{Mo}, \mathrm{Ni}_{4} \mathrm{Mo}, \mathrm{Me}_{3} \mathrm{C}_{2}, \mathrm{Me}_{23} \mathrm{C}_{6}$ and $\mathrm{Cr}_{3} \mathrm{Mn}_{5}$. 

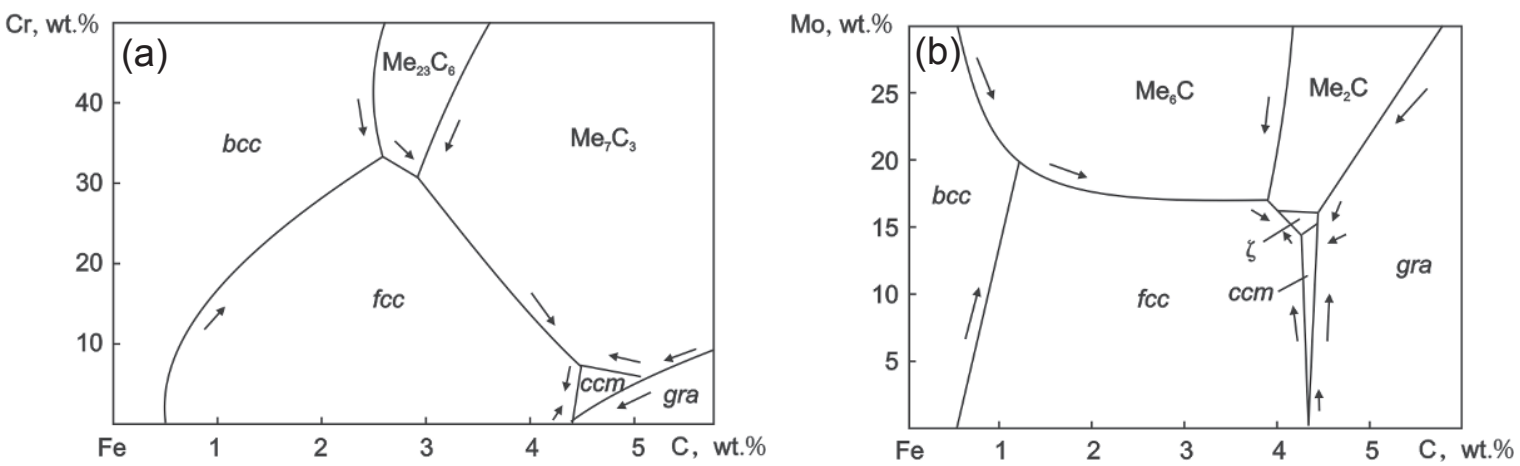

Fig. 2: Calculated phase diagrams for Fe-C-Cr (a) and Fe-C-Mo (b) systems

\subsection{Construction of thermophysical properties calculator}

Based on the full Gibbs free energy calculation by using the aforementioned equations, several thermophysical properties such as liquidus and solidus temperatures, latent heat, heat capacity can be calculated. Detailed explanation of the calculation is described in the previous article ${ }^{[1]}$.

Figure 3 shows the Graphical User Interface (GUI) program for thermophysical calculator. When the user can simply supply the composition data, calculating phases can be listed automatically; after calculation, phases formed during the solidification can be displayed in the window, and also can be output in excel form.
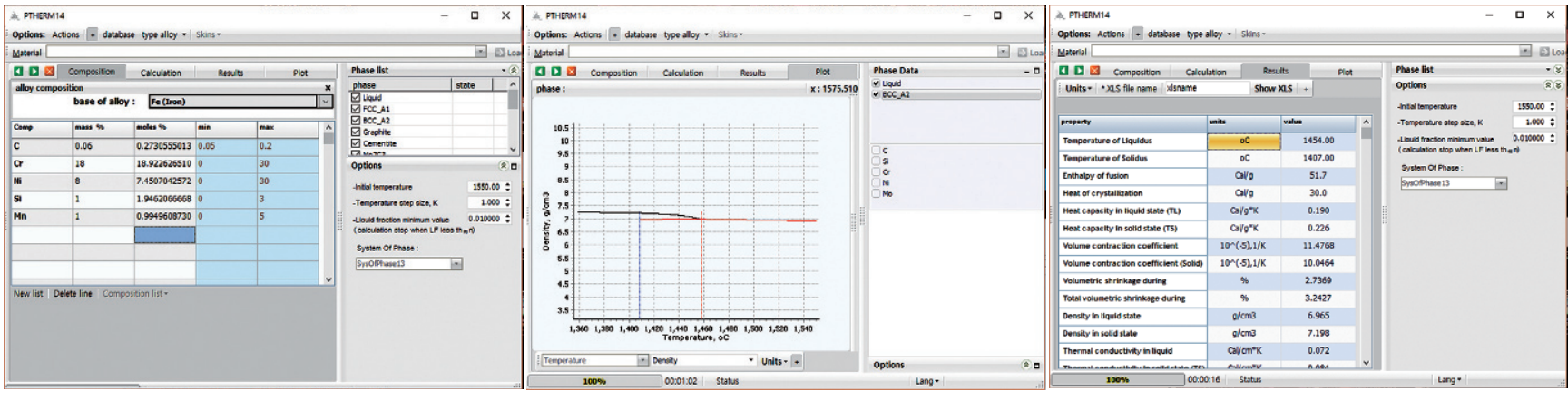

Fig. 3: GUI for thermophysical calculator

\section{Results and discussion}

Several Korean standard stainless steel alloys were taken as examples to calculate the themophysical properties of each phase in the Fe-C-Si-Cr-Mn-Ni system.

\subsection{Calculation of Fe-0.1C-1.0Si-13Cr-1Mn- 1Ni-1Mo (SCS3 Korean standard) system}

Figure 4 shows the phase composition and enthalpy of Fe-0.1C1.0Si-13Cr-1Mn-1Ni-1Mo (SCS3 Korean standard) alloy. In the range of temperatures from liquidus to $1,342{ }^{\circ} \mathrm{C}$, a liquid bcc solid solution is formed, as shown in Fig. 4(a), whereas a fcc solid solution is formed from $1,342{ }^{\circ} \mathrm{C}$ to $1,255{ }^{\circ} \mathrm{C}$ from a liquid. Up to temperature $1,246{ }^{\circ} \mathrm{C}$, carbide $\mathrm{Me}_{7} \mathrm{C}_{3}$ is formed together with fcc solid solution. At a lower temperature, ferrite is formed with these phases. At $1,219{ }^{\circ} \mathrm{C}$, the part of a liquid phase is less than $1 \%$.

In Fig. 4(b), sharp decrease in enthalpy is found at an initial stage of solidification. In the temperature range of alloy
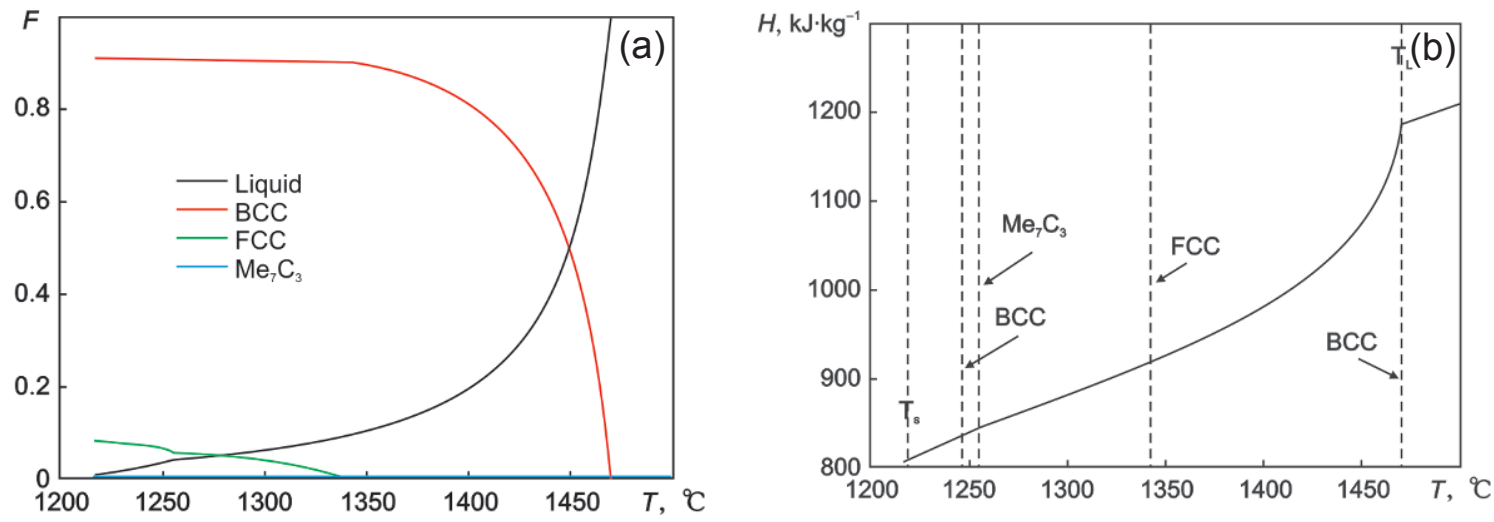

Fig. 4: Phase composition (a) and enthalpy (b) of SCS3 stainless steel as a function of temperature 
solidification, $375 \mathrm{~kJ} \cdot \mathrm{kg}^{-1}$ of latent heat are released, and $90 \%$ bec solid solution, $8 \%$ fcc solid solution and approximately $0.5 \%$ carbide $\mathrm{Me}_{7} \mathrm{C}_{3}$ are formed.

\subsection{Calculation of Fe-0.06C-1.0Si-13Cr-1Mn- 4Ni (SCS5) system}

Figures 5 and 6 show the Fe-0.06C-1.0Si-13Cr-1Mn-4Ni (SCS5) alloy. The liquidus temperature is $1,467{ }^{\circ} \mathrm{C}$. In the range from the liquidus temperature up to $1,389{ }^{\circ} \mathrm{C}$, the bcc solid solution is precipitated from melt, as shown in Fig. 5(a). In the temperature range of $1,389-1,258{ }^{\circ} \mathrm{C}$, a binary eutectic
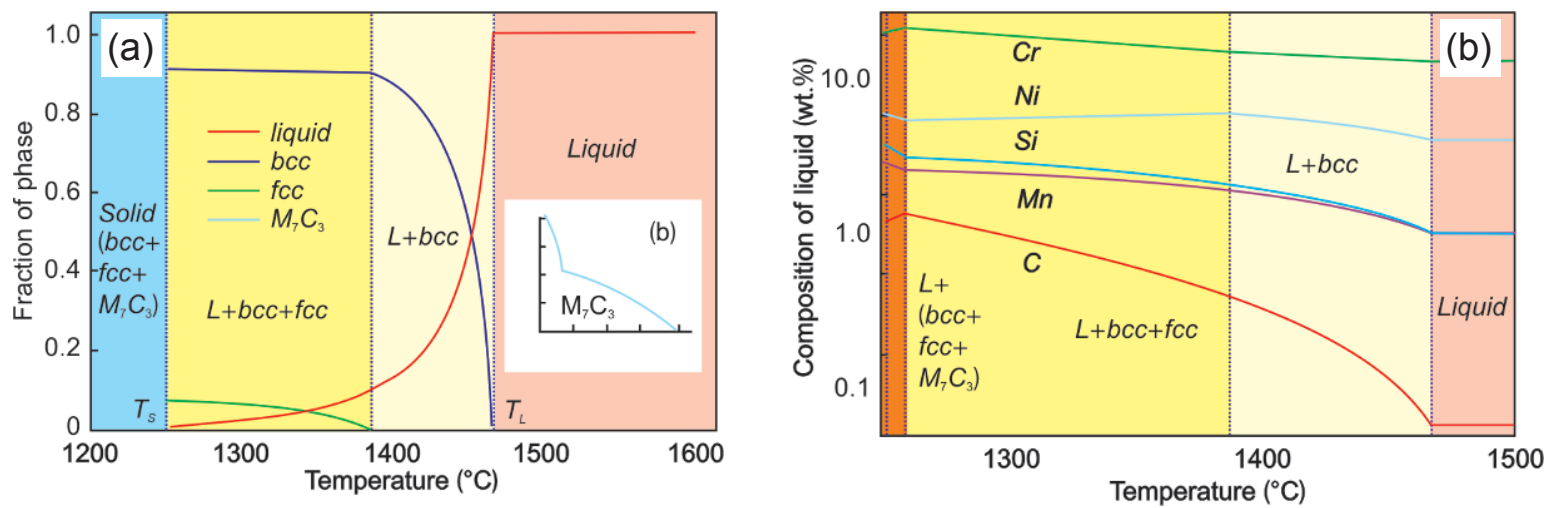

Fig. 5: Temperature dependence of fraction of liquid and solid phases (a) and liquid phase composition during solidification of SCS5 alloy (b)
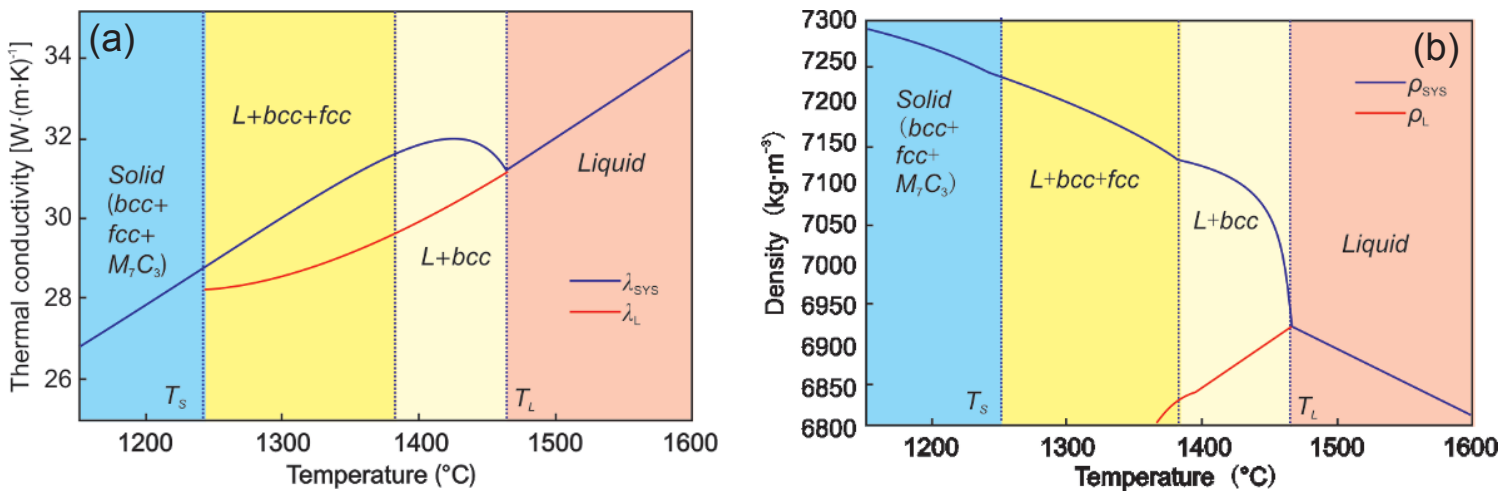

Fig. 6: Temperature dependence of thermal conductivity (a) and density (b) during solidification of SCS5 alloy

Figure 6 shows the change of thermal conductivity and density with temperature. As shown in Fig. 6(a), thermal conductivity decreases with temperature decreases above the liquidus temperature, however increases sharply below the liquidus temperature, and then gradually decreases again. Density also has a similar trend, the density sharply increases just below the liquid temperature, and then fcc solid solution is formed. In the interval of alloy solidification, $346 \mathrm{~kJ} \cdot \mathrm{kg}^{-1}$ of latent heat are released.

\subsection{Calculation of Fe-0.06C-1.0Si-13Cr-1Mn- 4Ni (SCS5) system}

Figures 7 and 8 show the Fe-0.06C-1Si-18Cr-1Mn-8Ni (SCS13) alloy. The temperature of liquidus equals $1,437^{\circ} \mathrm{C}$.

In the case of non-equilibrium solidification based on Scheil model, at the range from the liquidus temperature down to 1,393

is formed consisting of fcc and bcc solid solution. Below the temperature $1,251{ }^{\circ} \mathrm{C}$, where the liquid fraction is less than $1 \%$, ternary eutectic (fcc solid solution-bcc solid solution$\mathrm{Me}_{7} \mathrm{C}_{3}$ carbide) is formed. In the end of solidification, bcc solid solution $(92 \%)$, fcc solid solution (8\%), carbide $\mathrm{Me}_{7} \mathrm{C}_{3}$ (approximately $0.2 \%$ ) are formed. The sequence of phase forming is: bcc solid solution in the initial phase, the binary eutectic (bcc and fcc solid solutions) and ternary eutectic containing bcc-phase, fcc-phase and carbide $\mathrm{Me}_{7} \mathrm{C}_{3}$. Figure 5 (b) shows the distribution of each element composition of the alloy in the melt. 


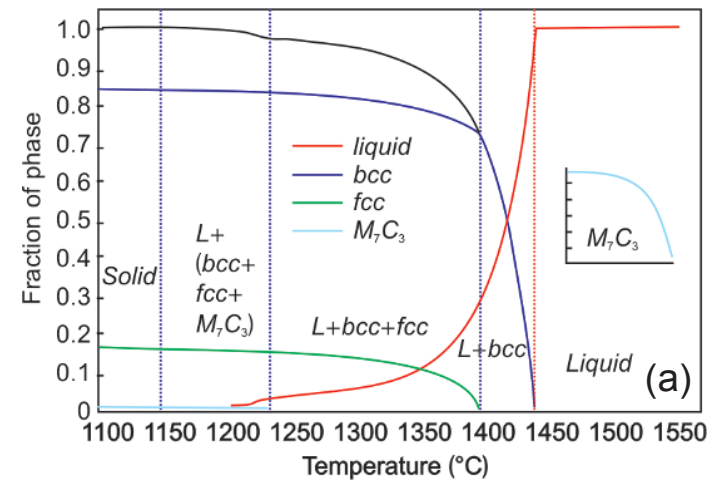

Fig. 7: Phase fraction (a) and enthalpy

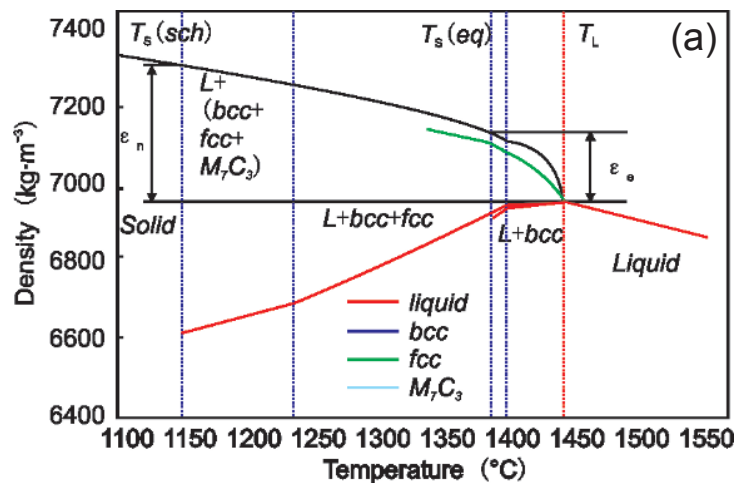

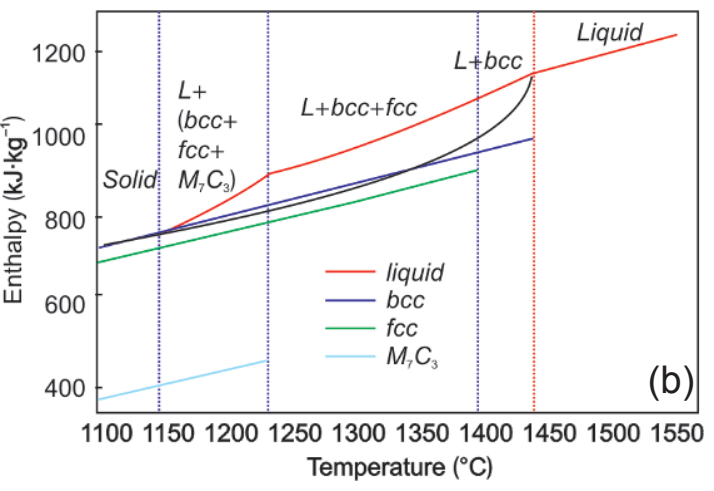

(b) of SCS 13 steel as a function of temperature

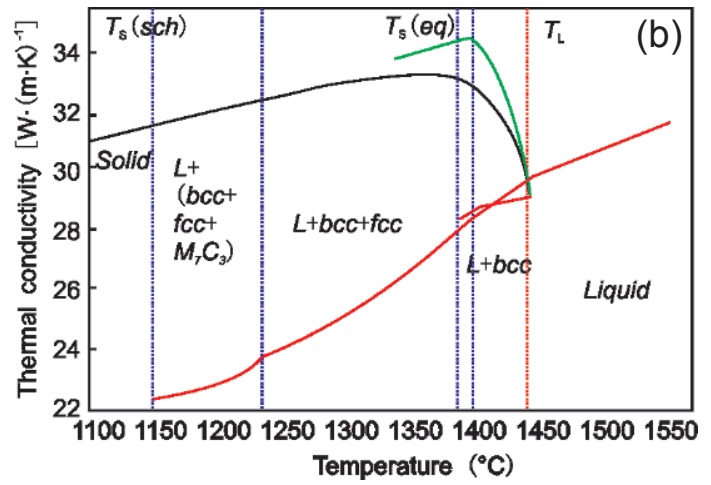

Fig. 8: (a) temperature dependence of liquid phase density (red) and density of alloy during equilibrium (green) and non-equilibrium (black) solidification; (b) temperature dependence of liquid phase (red) and alloy thermal conductivity during equilibrium (green) and nonequilibrium (black) solidification

equilibrium solidification, the bcc solid solution formation takes place at the temperature from liquidus $\left(1,437^{\circ} \mathrm{C}\right)$ to equilibrium solidus $\left(1,381{ }^{\circ} \mathrm{C}\right)$. Below the temperature $1,392{ }^{\circ} \mathrm{C}$, FCC solid solution is formed together with bcc solid solution. Final structure of alloy consists of bcc and fcc phases. However it is found that the density of alloy in the case of equilibrium solidification is lower than the case of non-equilibrium solidification at the same temperature. Further decrease in temperature leads to an increase in density of the alloy and a decrease in the density of the residual melt due to change in its composition owing to precipitating of solid phase enriched by high-density components.

Equilibrium and non-equilibrium solidification calculations affect the results of solidus temperature, latent heat and volume shrinkage $\varepsilon$ at solidification $\left(\varepsilon_{e}=0.026\right.$ and $\varepsilon_{n}=0.051$ in Fig. 8(a), where $\left.\varepsilon=\left(\rho_{\mathrm{s}}-\rho_{\mathrm{L}}\right) / \rho_{\mathrm{L}}\right)$. The large shrinkage of solidification under non-equilibrium conditions is connected with essentially large temperature range of solidification of an alloy and hence of greater quantities of change of volume during solidification and cooling of co-existing phases. For the same reason, latent heat of the alloy in non-equilibrium conditions exceeds the value for equilibrium conditions.

The thermal conductivity of the alloy, as shown in Fig. 8(b), increases during the equilibrium and non-equilibrium solidification due to the lower thermal conductivity of the liquid phase in comparison with solid phase, and all the thermal conductivity decreases as temperature decreases.

Figure 9 shows the changes in the element concentration of $\mathrm{C}, \mathrm{Si}, \mathrm{Mn}, \mathrm{Cr}$ and $\mathrm{Ni}$ in the liquid and solid phases (bcc, fcc and $\mathrm{M}_{7} \mathrm{C}_{3}$ ) formed at different temperatures during non-equilibrium solidification of the alloy.

As shown in Fig. 9 (a) and (b), the changes in the concentration of $\mathrm{Cr}$ in the melt during the formation of the bcc solid solution is insignificant since the distribution coefficient $k$ of $\mathrm{Cr}$ is closed to unity.

When fcc solid solution is formed below liquidus temperature, distribution coefficient $k$ becomes under unity, resulting in the considerable enrichment of $\mathrm{Cr}$ melt and a corresponding increase in concentration of $\mathrm{Cr}$ in the bcc solid solution, as shown in Fig. 9 (a), (b) and (c).

At the final stage of solidification during formation of carbide $\mathrm{Me}_{7} \mathrm{C}_{3}$, which contains up to $80 \% \mathrm{Cr}$, as well as $10 \% \mathrm{C}$ and no $\mathrm{Si}$ [Fig. 9 (d)], the significant reduction of $\mathrm{Cr}$ content in the fcc and bcc together with the Ni enriching of liquid phase and fcc solid solution is found in Fig. 9 (a) and (c).

\section{Conclusions}

The calculator which can calculate thermophysical properties of stainless steel composed of 8 components with iron base alloy was developed. Through calculating the thermophysical properties for several Korean standard stainless steel alloys, the 

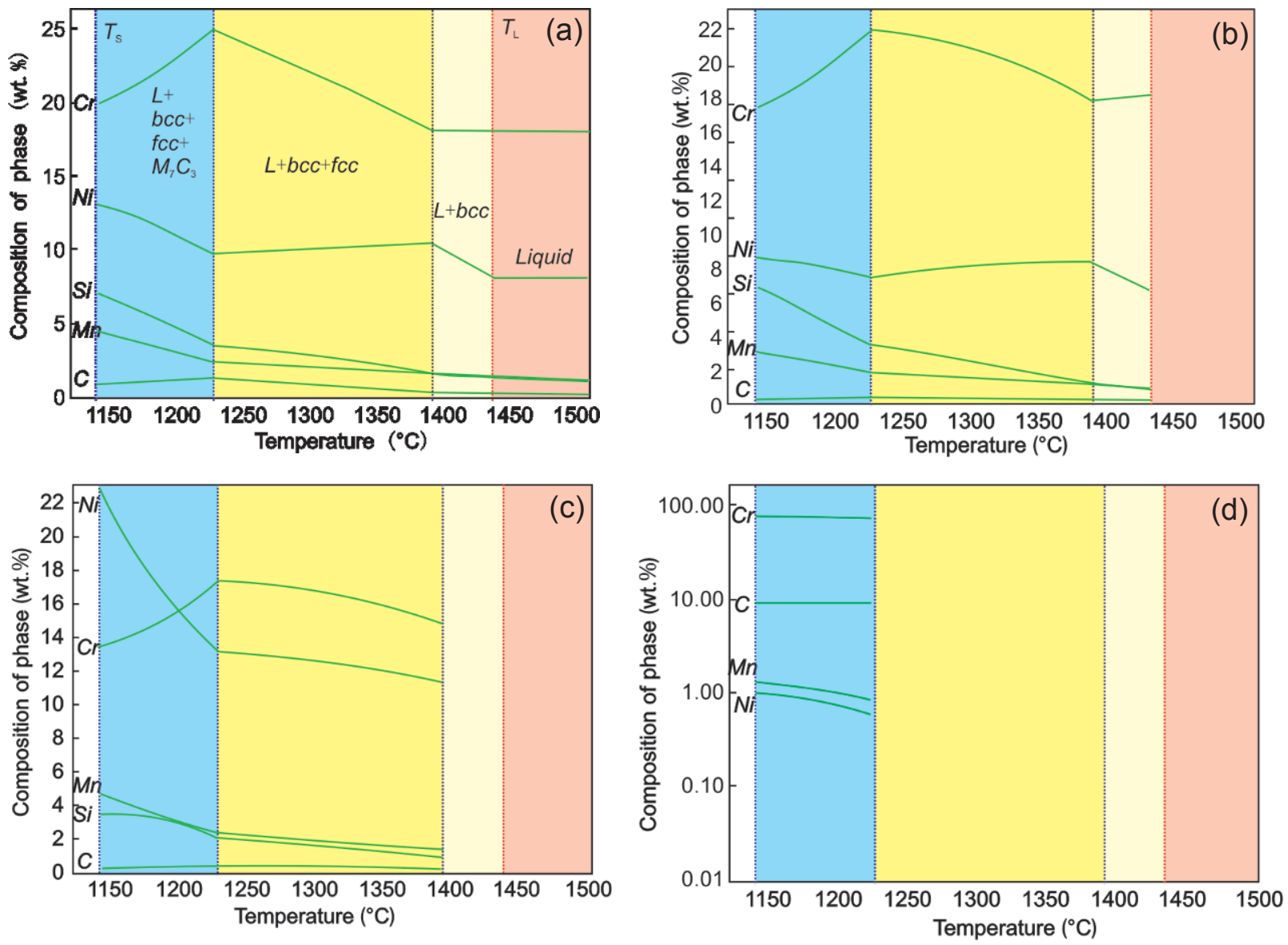

Fig. 9: Temperature dependence of composition of liquid phase (a), BCC solid solution (b), FCC solid solution (c) and carbide $\mathrm{Me}_{7} \mathrm{C}_{3}$ (d) during the non-equilibrium solidification

following conclusions can be drawn:

(1) The calculator can evaluate the thermophysical properties of the phases formed such as density, heat capacity, enthalpy, latent heat, etc, based on full Gibbs energy for each phase.

(2) Generally, fcc solid solution, bcc solid solution, $\mathrm{Me}_{7} \mathrm{C}_{3}$ type carbides are found in most stainless steels, and their fractions of phases are different with the composition of the alloys.

(3) Equilibrium and non-equilibrium solidification calculation show different liquidus and solidus, density, thermal conductivity values, which is very important to assess solidification behavior of the stainless steels.

This study will help non-skilled foundry engineers to have their own thermophysical properties for the simulation of the casting processes, in the field of not only stainless steels but also other alloy systems such as aluminum, copper, zinc, etc.

\section{References}

[1] Cho I-S, Yoo S-M, Golod V M, et al. Calculation of thermophysical properties of iron casting alloys. Int. J. of Cast Metals Research, 2009, 22(4): 43-46.

[2] Lacaze J, Sundman B. An assessment of the Fe-C-Si system. Metall. Trans., 1991, 22A(10): 2211-2223.
[3] Miettinen J. Reassessed termodynamic solution phase data for ternary Fe-C-Si system. Calphad, 1998, 22(2): 231-256.

[4] Andersson J O, Sundman B. Thermodynamic properties of the Cr-Fe system. Calphad, 1987, 11(1): 83-92.

[5] Andersson J O. A Thermodynamic evaluation of the $\mathrm{Fe}-\mathrm{C}-\mathrm{Cr}$ system. Metall. Trans., 1988, 19A(3): 627-636.

[6] Lee B J, Lee D N. A thermodynamic study on the Mn-C and Fe-Mn systems. Calphad, 1989, 13(4): 345-354.

[7] Lee B J, Lee D N. A thermodynamic study on the Fe-Mn-C system. Calphad, 1989, 13(4): 355-365.

[8] Huang W. An assessment of the Fe-Mn system. Calphad, 1989, 13(3): 243-252.

[9] Huang W. A Thermodynamic assessment of the Fe-Mn-C system. Metall. Trans., 1990, 21A(8): 2115-2123.

[10] Huang W. Termodynamic assessment of the Mn-C system. Scand. J. Metall., 1990, 19(1): 26-32.

[11] Gabriel A, Gustafson P, Ansara I. A thermodynamic evaluation of the C-Fe-Ni system. Calphad, 1987, 11(3): 203-218.

[12] Ohtani H, Suda H, Ishada K. Solid/liquid equilibria in $\mathrm{Fe}-\mathrm{Cu}$ based ternary systems. ISIJ International, 1997, 37(3): 207216.

[13] Hillert M, Qui C. A thermodynamic assessment of the Fe-CrNi-C system. Metall. Trans., 1991, 22A(10): 2187-2198.

[14] Lee B J. A thermodynamic evaluation of the Fe-Cr-Mn-C system. Metall. Trans. 1993, 24A(5): 1017-1025.

[15] Coughanowr C A, Ansara I, Lukas H L. Assessment of the CrSi system. Calphad, 1994, 18(2): 125-140. 